\title{
Pierre Robin sequence: Subdivision, data, theories, and treatment - Part 1: History, subdivisions, and data
}

\begin{tabular}{l} 
Access this article online \\
\hline Website: \\
www.amsjournal.com \\
\hline DOI: \\
10.4103/2231-0746.186133 \\
\hline Quick Response Code: \\
\end{tabular}

\author{
Kurt-W Bütow ${ }^{1,2,3}$, Roger Arthur Zwahlen ${ }^{4}$, Jean A. Morkel ${ }^{5}$, Sharan Naidoo' \\ ${ }^{1}$ Department of Maxillofacial and Oral Surgery, Facial Cleft Deformity Clinic, University of Pretoria, \\ ${ }^{2}$ Suite A2-Maxillofacial Surgery, The Wilgers Hospital, Pretoria, ${ }^{3}$ Department of Maxillofacial Surgery, \\ Division of Dentistry, College of Health Sciences, University of KwaZulu-Natal, Durban, ${ }^{5}$ Department \\ Maxillofacial and Oral Surgery, University of the Western Cape, Cape Town, South Africa, ${ }^{4}$ Discipline of \\ Oral and Maxillofacial Surgery, Faculty of Dentistry, University of Hong Kong, Hong Kong SAR, PR China
}

Address for correspondence: Prof. Roger Arthur Zwahlen, Oral and Maxillofacial Surgery, Faculty of Dentistry, The University of Hong Kong, 34 Hospital Road, Hong Kong SAR, PR China.

E-mail: zwahlen@hku.hk

\section{ABSTRACT}

Context: The disorder currently accepted as Pierre Robin syndrome/anomaly/sequence (PRS) has been plagued by controversy ever since initially being described. Controversy exists not only about the appropriate terminology and etiopathogenesis of the disorder but also about its management. Therefore, clinical findings and treatment outcomes of a large database of 266 PRS cases were compared with the current state of knowledge in scientific literature related to history, clinical description, diagnostic criteria, epidemiology, theories of oligohydramnios, mandibular catch-up growth, midfacial hyperplasia, and the timing of management. Aims of Part 1: Display disparities of the widely published subject of PRS that exist within the literature. Subjects and Methods: A literature search related to diagnostic criteria was compared to findings of one of the largest PRS databases worldwide. Results: Regarding diagnostic criteria two subdivisions, the Fairbairn-Robin triad (FRT) and the Siebold-Robin sequence (SRS) can be clearly distinguished. Both present with micrognathia and glossoptosis, the former with, the latter, however, without a palatal cleft. Conclusions: According to clear diagnostic criteria, PRS has to be subdivided in the future into FRT and SRS cases, as they may require different treatment approaches.

Keywords: Fairbairn-Robin triad, glossoptosis, micrognathia, Pierre Robin sequence, Siebold-Robin sequence

\section{INTRODUCTION}

In the first part of this publication series, the Pierre Robin sequence (PRS) has been analyzed and compared to various articles in the literature which describe its clinical features. The data sets of a large cleft lip and palate clinic at the Department of Maxillofacial and Oral Surgery of the University of Pretoria and The Wilgers Hospital, Pretoria, South Africa have been combed through with regard to the clinical appearance of cases suffering from PRS.

\section{SUBJECTS AND METHODS}

The electronic database PubMed was searched using the following keywords: Pierre Robin sequence; glossoptosis; micrognathia; Siebold-Robin sequence (SRS); Fairbairn-Robin triad (FRT).
- \#1 - (Pierre Robin sequence) OR (glossoptosis) OR (micrognathia) OR Siebold-Robin sequence (SRS) OR Fairbairn-Robin triad (FRT);

This is an open access article distributed under the terms of the Creative Commons Attribution-NonCommercial-ShareAlike 3.0 License, which allows others to remix, tweak, and build upon the work non-commercially, as long as the author is credited and the new creations are licensed under the identical terms.

For reprints contact: reprints@medknow.com

Cite this article as: Bütow KW, Zwahlen RA, Morkel JA, Naidoo S. Pierre Robin sequence: Subdivision, data, theories, and treatment - Part 1: History, subdivisions, and data. Ann Maxillofac Surg 2016;6:31-4. 
- \#2 - (profile) OR (morphology);

- \#3 - (\#1) and (\#2).

Combined free text terms with Boolean operators and truncation were applied. Restrictions were placed on English language of publication. A librarian was previously consulted for the search strategy.

The obtained citations from PubMed were exported to the bibliographic management software EndNote ${ }^{\circledast}$ (Thomson Reuters; Carlsbad, CA, USA). After a thorough refinement of titles and abstracts, hard copies of pertinent articles were obtained. Further connate publications could be gained by manual investigation of their references. All data were entered into an Excel spreadsheet for comparison.

A large database of 266 labeled PRS cases was screened for clinical description, history, diagnostic criteria, epidemiology, theories of oligohydramnios, mandibular catch-up growth, midfacial hyperplasia, and early management. These topics were compared with and discussed on the basis of current corresponding findings, theories, and recommendations related to treatment strategy in the literature.

\section{RESULTS}

\section{Literature review}

In his classic article of 1923, Pierre Robin introduced and described a novel entity. He coined the term glossoptosis in the presence of micrognathia and described its treatment. ${ }^{[1]}$ In a second publication, in 1934, the same author stated that someone before had mentioned that a cleft palate may be involved in this entity additionally with the two other, previously described clinical features. ${ }^{[2]}$

\section{Siebold-Robin sequence}

Information regarding the clinical diagnosis of Pierre Robin syndrome/anomalad/sequence gathered by the literature review is highly controversial, with some authors defining this/these entity/ entities as glossoptosis in the presence of micro-/retrognathia, with compromised airways as the only clinical diagnostic criteria. This description is consistent with the initial publications of Pierre Robin in which a cleft palate was not included as a clinical finding. ${ }^{[1,2]}$ As the combination of these two components, however, was previously described in 1835 by Von Siebold, ${ }^{[3]}$

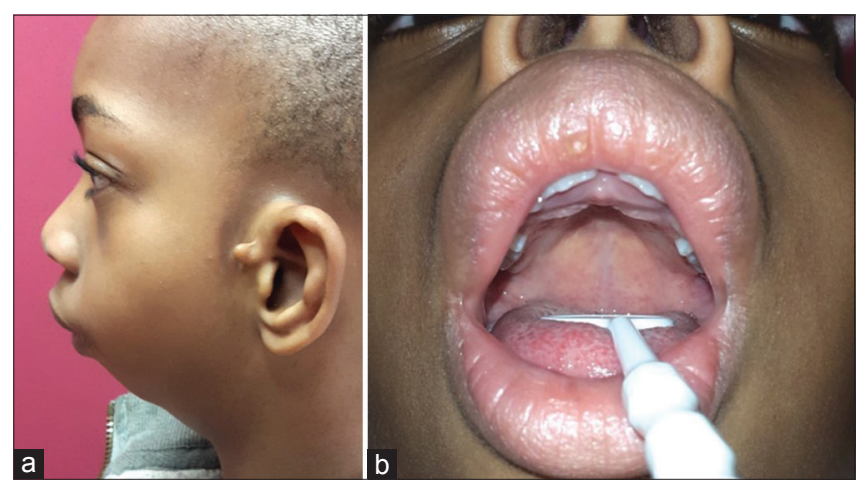

Figure 1: (a) Profile of a Siebold-Robin sequence patient. (b) No cleft palate this may be referred to as a true PRS subdivision. Since the descriptions by Von Siebold in 1835 and Pierre Robin in 1923 are similar, this subdivision will be described as the SRS ${ }^{[4]}$ [Figure 1].

\section{Fairbairn-Robin triad}

A cleft palate with airway compromise/obstruction or glossoptosis and micrognathia in patients had been described by Fairbairn in $1846 .{ }^{[5]}$ In the opinion of various authors, the presence of a cleft palate is not an absolute necessity for the diagnosis of a PRS. ${ }^{[6-10]}$ If that is a valuable diagnostic criterion, this entity should be described as the SRS. Others consider a cleft palate to be an absolute prerequisite for the diagnosis of a PRS. ${ }^{[11,12]}$ This therefore should be mediated a different subdivision of PRS. As this original triad was first published by Fairbairn in 1846 and Pierre Robin mentioned the cleft palate in his second publication of 1934, this triad, consisting of a cleft palate with features of the SRS, is regarded as a separate entity ${ }^{[4]}$ and will be referred to as the FRT ${ }^{[13]}$ [Figure 2a and b].

\section{Analysis of the clinical Pierre Robin sequence dataset}

The dataset of a large cleft lip and palate clinic in Pretoria, Republic of South Africa, has been analyzed concerning the incidences of an isolated cleft palate (ICP), PRS, SRS, and FRT [Table 1]. Furthermore, this dataset has been subdivided into different racial and gender groups [Table 2]. The FRT has been subdivided further according to those who presented with a hard and soft palate cleft (hPsP) and a soft palate (sP) cleft [Table 3].

\section{DISCUSSION}

In 1964 Grimm et al. ${ }^{[14]}$ stated that the Pierre Robin syndrome had been described long before Robin's publications by (a) Ullersperger (1822), (b) Moschner (1826), (c) Von Siebold (1835), and (d) Von Ammon (1842). The two stillborn infants described by Ullersperger ${ }^{[15]}$ cannot fall in the category of either SRS or FRT, as each case had additional deformities, such as oblique facial clefts. Moschner described two living patients, one with retrognathia and scoliosis, the other one with only a geniohypoplasia, small

$\begin{aligned} & \text { Table 1: Data: Clinic, isolated cleft palate, Pierre Robin } \\
& \text { sequence, Siebold-Robin sequence and Fairbairn-Robin } \\
& \text { triad }\end{aligned}$
\begin{tabular}{lcccc}
\hline Total Cleft & ICP* $\left.^{*} \%\right)$ & PRS (\%) & SRS (\%) & FRT (\%) \\
\hline 4158 & $1518(36.5)$ & $266(6.4)$ & $21^{* *}(0.5 ; 7.8)$ & $245(5.9 ; 92.2)$ \\
\hline${ }^{*}$ ICP=Isolated cleft palate; ${ }^{* *}=$ No cleft & &
\end{tabular}

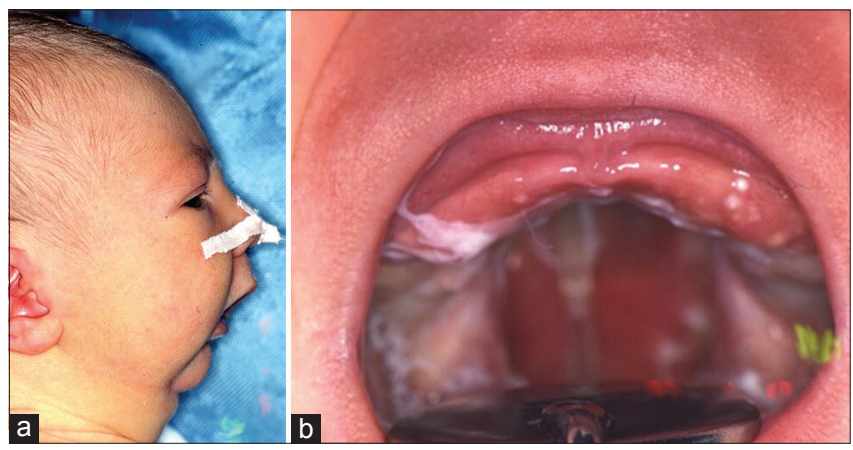

Figure 2: (a) Profile of a Fairbairn-Robin triad patient. (b) U-shaped wide palatal cleft 
Table 2: Race and gender

\begin{tabular}{lcccccccccc}
\hline & & \multicolumn{2}{c}{ PRS $(\%)$} & & \multicolumn{2}{c}{ SRS (\%) } & & \multicolumn{2}{c}{ FRT (\%) } \\
\cline { 3 - 4 } \cline { 8 - 9 } & & Male & Female & & Male & Female & & Male & Female \\
\hline White & 2527 & $89(3.5)$ & $116(4.6)$ & & $5(0.2)$ & $6(0.2)$ & & $84(3.3)$ & $110(4.4)$ \\
Black & 1377 & $24(1.7)$ & $23(1.7)$ & & $4(0.3)$ & $4(0.3)$ & & $20(1.5)$ & $19(1.4)$ \\
Indian & 133 & $8(6.0)$ & $4(3.0)$ & & $1(0.8)$ & $1(0.8)$ & & $7(5.3)$ & $3(2.3)$ \\
Cape Colored & 109 & $0(0)$ & $2(1.8)$ & & $0(0)$ & $0(0)$ & & $0(0)$ & $2(1.8)$ \\
\hline
\end{tabular}

Table 3: Fairbairn-Robin triad versus hard and soft palate cleft and soft palate cleft*

\begin{tabular}{|c|c|c|c|c|c|}
\hline \multicolumn{3}{|c|}{ ICP* } & \multicolumn{3}{|c|}{ FRT } \\
\hline Total ICP\# & hPsP** (\%) & $\mathbf{s P * * *}(\%)$ & Total FRT & hPsP (\%) & sP (\%) \\
\hline 1518 & 712 (46.9) & 768 (50.6) & 245 & $220(89.8)$ & $25(10.2)$ \\
\hline
\end{tabular}

tongue, and an isolated hard palate cleft. ${ }^{[16]}$ Again, neither of these two cases fit the mold of SRS or FRT. The case described by von Siebold presented with micrognathia and microglossia with glossoptosis ${ }^{[3]}$ and succumbed to asphyxia. This case might be considered to be the first true description of an SRS. To credit both Von Siebold and Pierre Robin (1923) with the description of this sequence, it should be denominated the SRS, a subdivision of the PRS. ${ }^{[4]}$ A second similar case description was published by Fäsebeck in 1842, ${ }^{[16]}$ a very rare clinical appearance of a tongue atresia/aglossia or a microglossia without muscles/hypoglossia, combined with severe micrognathia as in oromandibular limb hypogenesis syndromes. ${ }^{[17,18]}$ PRS mostly presents with microglossia, and the tongue is mostly positioned posteriorly into the pharyngeal cavity (SRS) or through the cleft palate into the pharyngeal cavity (FRT), causing glossoptosis. An aglossia or hypoglossia, on the other hand, usually does not lead to a true glossoptosis due to the rudimentary nonfunctional tongue. Therefore, this particular group of patients should not be allocated to the PRS diagnosis.

The patient described by Von Ammon in 1842 suffered from micrognathia, microglossia and an hPsP cleft. However, that patient had no glossoptosis or compromised airway, and therefore should not be diagnosed as a true FRT. ${ }^{[16]}$ St. Hilaire (1822) has often been quoted as having described this triad of cleft palate, micrognathia, and airway obstruction for the first time. ${ }^{[19]}$ However, in this literature review, it could not be verified that this specific description had ever been published, even though various authors referred to and quoted from it. ${ }^{[18-20]}$ Therefore, the triad of cleft palate associated with a mandibular micrognathia/ retrognathia and compromised/obstructed airways was most probably first described by Fairbairn in 1846 in two cases. ${ }^{[5]}$ Years later in 1911, after Fairbairn's and before Robin's publications, Shukowsky ${ }^{[20]}$ described one among three cases with glossoptosis and compromised airways as "stridor inspiratorius congenitus infantum." In recognition of Fairbairn being credited with the original description with the inclusion of the cleft palate and Pierre Robin in 1934 with the description of this triad, one should name it the FRT. This then becomes a second subdivision of the PRS. ${ }^{[4]}$ Currently, it seems that the general understanding among the craniofacial community is that the original description of the PRS should include a cleft palate. ${ }^{[6-10,12,18,21-26]}$
It has been stated that the presence of a wide and U-shaped cleft justifies the diagnosis of an FRT. ${ }^{[27]}$ Amaratunga found that similar proportions of $\mathrm{U}$ - and $\mathrm{V}$-shaped clefts were present amongst both the FRT and ICP groups, ${ }^{[28]}$ whereas some authors even specify that the type of cleft should be wide and U-shaped to justify the diagnosis. ${ }^{[27]}$ The wide U-shaped cleft palate (FRT) is certainly not an essential element for the diagnosis. ${ }^{[29]}$ According to the data analyzed from this cleft clinic database, eight cases presented with glossoptosis, a tongue that was folded sagittal and lodged into a relatively narrow palatal cleft ( 7 hPsP, 1 sP). One additional case with an sP cleft, presented with the tongue folded coronally and positioned posteriorly against the superior part of the $\mathrm{sP}$ and not into the relatively narrow sP cleft.

The $6.4 \%$ of patients with PRS reported in this database correspond to the standard percentage reported in the literature. Significantly fewer cases are documented in the SRS group. This could be due to (1) the possibility that there are fewer SRS cases or (2) that these cases lacking of a cleft palate are simply not referred to a cleft lip and palate clinic [Table 1]. In the white racial group, the majority of patients presenting with this type of sequence and triad were found to be females, whereas in the black racial group, patients of both genders were more equally represented. In the rather small Indian racial group, the majority of patients with the FRT deformity were males [Table 2]. The ratio of $\mathrm{hPsP}$ to $\mathrm{SP}$ of the ICP was $46.9-50.6 \%$, the balance of the percentage being isolated $\mathrm{hP}$, whereas the ratio for FRT cases was $89.8-10.2 \%$. Therefore, the vast majority of FRT has an hPsP cleft [Table 3].

Obviously most authors still consider diagnosing the SRS and the FRT as a PRS, therefore placing all their cases and clinical information under an all-encompassing clinical diagnostic umbrella. The majority of authors consider this oro-facial deformity as a triad, including the cleft palate. However, there is a reason to believe that there are two distinct subgroups among this diagnostic umbrella of PRS: In one racial group the females were predominately affected, and in other racial groups, the males. Isolated sP clefts seldom presented in patients of the FRT group. The subgroup SRS in this database was very small, probably due to fewer cases being affected, or due to the simple fact that these patients lacking of clefts were not referred to a cleft clinic.

\section{CONCLUSION}

According to clear diagnostic criteria, PRS has to be subdivided in the future into FRT and SRS cases, as they may require different treatment approaches.

\section{Declaration of patient consent}

The authors certify that they have obtained all appropriate patient consent forms. In the form the patient(s) has/have given his/her/their consent for his/her/their images and other clinical information to be reported in the journal. The patients understand that their names and initials will not be published and due efforts will be made to conceal their identity, but anonymity cannot be guaranteed. 


\section{Acknowledgement}

The authors would like to thank Mrs Jennilee Blom for her invaluable job as research assistant.

\section{Financial support and sponsorship Nil.}

\section{Conflicts of interest}

There are no conflicts of interest.

\section{REFERENCES}

1. Robin P. La glossoptose. Son diagnostic, ses conséquences, son traitement. Bull Acad Natl Med 1923;89:37-41.

2. Robin P. Glossoptosis due to atresia and hypotrophy of the mandible. Am J Dis Child 1934;48:541-7.

3. Von Siebold E. Micrognathia with breathing problems. Siebold's J (Göttingen) 1835:XV; 18.

4. Bütow KW, Zwahlen RA, editors. Pierre Robin sequence treatment. In: Cleft - Ultimate Treatment. $2^{\text {nd }}$ ed. Durban: Reach Publisher; 2016. p. 337-65.

5. Fairbairn P. Suffocation in an infant from retraction of the base of the tongue. Month J Med Sci 1846;6:280-1.

6. Igarashi M, Filippone MV, Alford BR. Temporal bone findings in Pierre Robin syndrome. Laryngoscope 1976;86:1679-87.

7. Elliott MA, Studen-Pavlovich DA, Ranalli DN. Prevalence of selected pediatric conditions in children with Pierre Robin sequence. Pediatr Dent 1995;17:106-11.

8. Vegter F, Hage JJ, Mulder JW. Pierre Robin syndrome: Mandibular growth during the first year of life. Ann Plast Surg 1999;42:154-7.

9. Bacher M, Bacher U, Göz G, Pham T, Cornelius CP, Speer CP, et al. Three-dimensional computer morphometry of the maxilla and face in infants with Pierre Robin sequence - A comparative study. Cleft Palate Craniofac J 2000;37:292-302.

10. Breugem CC, Mink van der Molen AB. What is Pierre Robin sequence? J Plast Reconstr Aesthet Surg 2009;62:1555-8.

11. van den Elzen AP, Semmekrot BA, Bongers EM, Huygen PL, Marres HA. Diagnosis and treatment of the Pierre Robin sequence: Results of a retrospective clinical study and review of the literature. Eur J Pediatr 2001;160:47-53.

12. Laitinen SH, Heliövaara A, Ranta RE. Craniofacial morphology in young adults with the Pierre Robin sequence and isolated cleft palate. Acta Odontol Scand 1997;55:223-8.

13. Hoogendijk CF, Bütow KW. Fairbairn-Robin appearance: A controversial syndrome, 171 cases. J Craniomaxillofac Surg 2008;36 Suppl:15 [O.059].

14. Grimm G, Pfefferkorn A, Taatz H. Clinical significance of Pierre Robin syndrome and its treatment. Dtsch Zahn Mund Kieferheilkd Zentralbl Gesamte 1964:43:385-416.

15. Ullersperger JP. Pathologisch-anatomische Beschreibung zweyer Missgeburten ["Description of two spontanous abortion cases"]. Germany: Inaugural-Schrift ["Dissertation"] - University of Würzburg, 1822

16. Meyer R, Schwalbe E. Discussion concerning the reasoning and causes of micrognathia. Studien Pathol Entwickl (Jena) 1920;11:405-11.

17. Meundi MA, Nair GR, Sreenivasan P, Raj AC. Oromandibular limb hypogenesis syndrome type IIB: Case report of hypoglossia-hypodactyly. Case Rep Dent 2013;2013:370695.

18. Gorlin RJ, Cohen MM, Levin LS, editors. Robin sequence. In: Syndromes of the Head and Neck. New York, Oxford: University Press; 1990. p. 860-5, 913-7.

19. St-Hilaire H, Buchbinder D. Maxillofacial pathology and management of Pierre Robin sequence. Otolaryngol Clin North Am 2000;33:1214-56.

20. Randall P, Krogman WM, Jahins S. Pierre Robin and the syndrome that bears his name. Cleft Palate J 1965;36:237-46.

21. Daskalogiannakis J, Ross RB, Tompson BD. The mandibular catch-up growth controversy in Pierre Robin sequence. Am J Orthod Dentofacial Orthop 2001;120:280-5.

22. Figueroa AA, Glupker TJ, Fitz MG, BeGole EA. Mandible, tongue, and airway in Pierre Robin sequence: A longitudinal cephalometric study. Cleft Palate Craniofac J 1991;28:425-34.

23. Glander K $2^{\text {nd }}$, Cisneros GJ. Comparison of the craniofacial characteristics of two syndromes associated with the Pierre Robin sequence. Cleft Palate Craniofac J 1992;29:210-9.

24. Holder-Espinasse M, Abadie V, Cormier-Daire V, Beyler C, Manach Y, Munnich A, et al. Pierre Robin sequence: A series of 117 consecutive cases. J Pediatr 2001;139:588-90.

25. Laitinen SH, Ranta RE. Cephalometric measurements in patients with Pierre Robin syndrome and isolated cleft palate. Scand J Plast Reconstr Surg Hand Surg 1992;26:177-83.

26. Ozkan KU, Coban YK, Uzel M, Ergun M, Oksuz H. Pierre Robin sequence with esophageal atresia and congenital radioulnar synostosis. Cleft Palate Craniofac J 2006;43:317-20.

27. Shprintzen RJ. Pierre Robin, micrognathia, and airway obstruction: The dependency of treatment on accurate diagnosis. Int Anesthesiol Clin 1988;26:64-71.

28. Amaratunga NA. A comparative clinical study of Pierre Robin syndrome and isolated cleft palate. Br J Oral Maxillofac Surg 1989;27:451-8.

29. Bütow KW, Hoogendijk CF, Zwahlen RA. Pierre Robin sequence: Appearances and 25 years of experience with an innovative treatment protocol. J Pediatr Surg 2009;44:2112-8. 